\title{
Finnish Version of the Eating Assessment Tool (F-EAT-10): A Valid and Reliable Patient-reported Outcome Measure for Dysphagia Evaluation
}

\author{
Pia Järvenpää ${ }^{1}$ (D ) Jonna Kuuskoski ${ }^{2}$ Petra Pietarinen ${ }^{1} \cdot$ Mari Markkanen-Leppänen ${ }^{1} \cdot$ Hanna Freiberg ${ }^{2}$ \\ Miia Ruuskanen ${ }^{2}$. Jami Rekola ${ }^{2}$ - Taru Ilmarinen ${ }^{1}$ - Teemu J. Kinnari ${ }^{1}$. Timo J. Autio ${ }^{3,4,5}$. Elina Penttilä6 \\ Marika S. Muttilainen ${ }^{7} \cdot$ Annika Laaksonen $^{8} \cdot$ Lotta Oksanen $^{8} \cdot$ Ahmed Geneid $^{8} \cdot$ Leena-Maija Aaltonen $^{1}$
}

Received: 20 May 2021 / Accepted: 30 August 2021 / Published online: 13 September 2021

(c) The Author(s) 2021

\begin{abstract}
Our aim was to validate a Finnish version of the Eating Assessment Tool (F-EAT-10) for clinical use and to test its reliability and validity in a multicenter nationwide study. Normative data were acquired from 180 non-dysphagic participants (median age 57.0 years, $62.2 \%$ female). Dysphagia patients ( $n=117$, median age 69.7 years, $53.0 \%$ female) referred to fiberoptic endoscopic evaluation of swallowing (FEES) completed F-EAT-10 before the examination and after 2 weeks. Patients underwent the 100-ml water swallow test (WST) and FEES was evaluated using the following three scales: the Yale Pharyngeal Residue Severity Rating Scale, Penetration-Aspiration Scale, and the Dysphagia Outcome Severity Scale. An operative cohort of 19 patients (median age 75.8 years, 57.9\% female) underwent an endoscopic operation on Zenker's diverticulum, tight cricopharyngeal muscle diagnosed in videofluorography, or both. Patients completed the F-EAT-10 preoperatively and 3 months postoperatively. The cut-off score for controls was $<3$ (sensitivity $94.0 \%$, specificity $96.1 \%$ ) suggesting that $\geq 3$ is abnormal. Re-questionnaires for test-retest reliability analysis were available from 92 FEES patients and 123 controls. The intraclass correlation coefficient was excellent for the total F-EAT-10 score $(0.93,95 \%$ confidence interval $0.91-0.95)$. Pearson correlation coefficients were strong $(p<0.001)$ for each of the questions and the total score. Internal consistency as assessed by Cronbach's alpha was excellent (0.95). Some correlations between findings in FEES and 100-ml WST with F-EAT-10 were observed. The change in subjective symptoms of operative patients paralleled the change in F-EAT-10. F-EAT-10 is a reliable, valid, and symptom-specific patient-reported outcome measure for assessing dysphagia among Finnish speakers.
\end{abstract}

Keywords Dysphagia $\cdot$ EAT-10 $\cdot$ Patient-reported outcome measure $\cdot$ Dysphagia screening $\cdot$ Swallowing $\cdot$ Deglutition

Pia Järvenpää

pia.jarvenpaa@fimnet.fi

1 Department of Otorhinolaryngology - Head and Neck Surgery, Helsinki University Hospital and University of Helsinki, Helsinki, P.O. Box 263, FI-00029, Finland

2 Department of Otorhinolaryngology - Head and Neck Surgery, Turku University Hospital and University of Turku, Turku, Finland

3 Department of Otorhinolaryngology - Head and Neck Surgery, Oulu University Hospital, Oulu, Finland

4 PEDEGO Research Unit, University of Oulu, Oulu, Finland
5 Medical Research Center Oulu, Oulu, Finland

6 Department of Otorhinolaryngology - Head and Neck Surgery, Kuopio University Hospital and University of Eastern Finland, Kuopio, Finland

7 Department of Rehabilitation and Psychosocial Support, Tampere University Hospital and Faculty of Social Sciences, University of Tampere, Tampere, Finland

8 Department of Otorhinolaryngology and Phoniatrics Head and Neck Surgery, Helsinki University, Hospital and University of Helsinki, Helsinki, Finland 


\section{Introduction}

Difficulty in swallowing, or dysphagia, is a common symptom related to many diseases. Dysphagia affects approximately $20 \%$ of the general population, $33 \%$ of individuals $>80$ years living independently, and half of hospitalized patients [1-4]. Many neurological diseases affect swallowing and up to $80 \%$ of patients with acute stroke suffer from dysphagia [5]. In addition, esophageal and functional dysphagia, when the patient has subjective swallowing problems, but the swallowing is normal, usually affect young- and middle-aged adults. As dysphagia is also often unreported by patients and unrecognized and neglected by clinicians, the true prevalence of dysphagia is likely even higher than reported [6]. Dysphagia can lead to dehydration, malnutrition, social isolation, mental problems, pneumonia, and even death [6, 7]. In addition to its personal burden, dysphagia also leads to substantial healthcare costs [8].

Patient history and clinical examination are of utmost importance in dysphagia diagnostics. Dysphagia can be classified as either oropharyngeal or esophageal; a careful patient interview helps to identify the anatomical site and likely cause of dysphagia in most cases. In patients with oropharyngeal dysphagia, safety and efficiency of swallowing should be evaluated. Instrumental examinations, such as videofluorography or fiberoptic endoscopic evaluation of swallowing (FEES), are often necessary. Diagnostic tools in esophageal dysphagia include transnasal esophagoscopy, esophagogastroscopy, high-resolution manometry, or multichannel intraluminal impedance and $\mathrm{pH}$ monitoring. However, overuse of instrumental examinations is neither necessary nor cost effective. In dysphagia diagnostics, validated screening tools should be used to evaluate symptom severity and treatment outcomes. Several patient-reported outcome measures for oropharyngeal dysphagia assessment are available [9]. Some questionnaires are more generic, such as the Swallowing Quality of Life Questionnaire (SWAL-QOL) [10] or the Dysphagia Handicap Index (DHI) [11], whereas some are more disease specific, such as the M.D. Anderson Dysphagia Inventory (MDADI), which was developed to evaluate dysphagia-related quality-of-life among patients with head and neck cancer [12]. Many of these questionnaires are very detailed, extensive, and time consuming and are thus too cumbersome for clinical practice.

In 2008, Belafsky et al. developed the Eating Assessment Tool (EAT-10) to provide examiners with a rapid and easily scored dysphagia instrument that can be used at each patient visit to assess severity of dysphagia symptoms, quality of life, and treatment efficacy [13]. EAT10 consists of 10 items related to the main aspects of dysphagia. Each item is rated on a 5-point scale from no difficulty ( 0 points) to severe difficulty ( 4 points). The sum of points from all 10 items is calculated and a score $>2$ points is considered suggestive of dysphagia [13]. EAT10 is easy to use and takes less than 2 min to complete [13-18]. EAT-10 has been shown to be a valid clinical tool and has good internal consistency and test-retest reliability [13]. In Europe, EAT-10 has been translated and validated in Spanish [14], Italian [15], European Portuguese [16], Swedish [19], Turkish [17], Greek [20], Dutch [21], and French [22]. The aim of this study was to validate a Finnish version of EAT-10 (F-EAT-10) to determine the clinical need for such assessment in Finland among Finnish speakers. We also aimed to investigate if F-EAT-10 can predict certain findings (particularly aspiration) and if this tool is applicable in a follow-up to assess changes in dysphagia symptoms.

\section{Materials and Methods}

\section{Translation of EAT-10 into Finnish}

Written consent to translate and validate EAT-10 was requested from Peter Belafsky, who owns the copyright of the original EAT-10. We used the forward-backward method in translation according to Wild et al. [23]. A native Finnish-speaking professional translator performed the forward translation from English to Finnish. A back translation was performed by a native English-speaking professional translator. Two experienced laryngologists (L-MA and PJ) also independently translated EAT-10 into Finnish. No critical differences were found after comparison of the translations. The final F-EAT-10 was achieved after laryngologists (L-MA, PJ, PP, TK, TI) of the Helsinki University Hospital, Department of Otorhinolaryngology - Head and Neck Surgery (HUH ORL-HNS) discussed F-EAT-10 together and made minor changes to improve the Finnish language (Table 1). A pilot test of F-EAT-10 was performed by L-MA and PJ on 10 dysphagic outpatients from HUH ORL-HNS (median age 55.2 years, range $18-79,60 \%$ male). After reviewing the patient's comments, no changes to F-EAT-10 questionnaire were deemed necessary.

\section{Controls and Patients}

\section{Controls}

Otological and audiological outpatients recruited from HUH ORL-HNS served as controls. Controls were aged $>18$ and $<85$ years and had no history of symptoms, examinations, or treatment related to dysphagia or dysphonia, no history of difficult xerostomia or difficult reflux symptoms, 
Table 1 Items from the Finnish version of EAT-10 (F-EAT-10)

\begin{tabular}{lll}
\hline Item & Original version & Finnish version \\
\hline & To what extent are the following scenarios problematic for you? & Missä määrin seuraavat tilanteet ovat teille ongelmallisia? \\
2 & My swallowing problem has caused me to lose weight & Nielemisvaivani on aiheuttanut minulle painon laskua \\
3 & My swallowing problem interferes with my ability to go out for meals & Nielemisvaivani häiritsee sitä, voinko mennä ulos syömään \\
4 & Swallowing liquids takes extra effort & Nesteiden nieleminen on työlästä \\
5 & Swallowing solids takes extra effort & Kiinteän ruoan nieleminen on työlästä \\
6 & Swallowing pills takes extra effort & Tablettien nieleminen on työlästä \\
7 & Swallowing is painful & Nieleminen on kivuliasta \\
8 & The pleasure of eating is affected by my swallowing & Nielemiseni vaikuttaa ruokailusta nauttimiseen \\
9 & When I swallow food sticks in my throat & Niellessäni ruoka takertuu kurkkuuni \\
10 & Swallowing is stressful & Yskin syödessäni \\
\hline
\end{tabular}

and no diagnosed neurological diseases (except migraine). Moreover, controls had no history of diagnosed head and neck cancer, upper gastrointestinal or upper respiratory tract malignancy, or surgical procedures in upper aerodigestive tract. However, history of adenotomy and tonsillectomy were acceptable if the operation was performed $>1$ year previously and if postoperative recovery was uneventful. The nurse interviewed the controls regarding the inclusion criteria before entry into the study. All controls completed the F-EAT-10 and the nurse measured the time required to complete the questionnaire to obtain information on the feasibility of F-EAT-10. To evaluate the test-retest reliability, the controls were asked to complete F-EAT-10 again after 2 weeks. The controls received a text message as a reminder to complete and return the F-EAT-10.

\section{Patients}

The study consisted of the following two patient groups with dysphagia: FEES patients and those operated endoscopically due to Zenker's diverticulum, tight cricopharyngeal muscle, or both (operative patients). Included patients were $>18$ years, native Finnish speakers, without notable psychiatric or cognitive disease, and able to complete F-EAT-10 independently.

\section{FEES Patients}

Patients with suspected oropharyngeal dysphagia who underwent FEES were recruited between September 2018 to June 2020 from four university hospital otorhinolaryngological and phoniatric departments (Helsinki, Kuopio, Tampere, Turku), one secondary care hospital ear, nose, and throat (ENT) department (Vaasa Central Hospital), and one secondary care hospital phoniatric (Central Ostrobothnia Central Hospital) department. F-EAT-10 was completed before FEES and again after 2 weeks to assess test-retest reliability.
A text message or a phone call served as a reminder to complete and return the re-questionnaire. Because of possible symptom change during the 2 -week period, the re-questionnaire also included a question to assess if the patient's symptoms were the same as 2 weeks earlier $(0=$ no symptoms, $1=$ less symptoms, 2 = same symptoms, $3=$ slightly more symptoms, $4=$ much more symptoms). Moreover, this also allowed assessment of criterion validity of whether F-EAT10 could show possible symptom changes of FEES patients during the follow-up.

\section{FEES Protocol and Water Swallow Test}

In FEES, swallowing was evaluated with a transnasally passed thin, diameter of 2.6 or $3.4 \mathrm{~mm}$, videoendoscope when the patient was given different textures and bolus volumes [24]. The bolus textures used were liquid (water), nectar (blueberry soup), semi-solid (puree), and solid (cookie). The examination started with small boluses (the tip of a teaspoon) and continued to larger ones (maximum tablespoon). The examination was modified according to patient swallowing ability. An experienced ENT specialist or a phoniatrician with a speech and language pathologist (SLP) or an experienced SLP alone performed and evaluated their own FEES tests using the following three scales: the Yale Pharyngeal Residue Severity Rating Scale [25], the Penetration-Aspiration Scale (PAS) [26], and the Dysphagia Outcome Severity Scale (DOSS) [27]. In addition, the following were evaluated: saliva retention in vallecula and pyriform sinuses, movements of lateral pharyngeal walls and base of the tongue, velopharyngeal closure, vocal fold closure, and sensory findings of arytenoids and tip of the epiglottis by touching with an endoscope. When evaluating the patient's Yale Pharyngeal Residue Severity Rating Scale and PAS, the worst result was marked as the final result. The baseline F-EAT-10 score and FEES findings were compared to examine how the symptoms correlated with the findings 
(criterion validity). All FEES patients underwent the 100-ml water swallow test (WST) [28]. In the WST, the patient was asked to drink $100 \mathrm{ml}$ water continuously at his or her own pace. The number of swallows needed, possible coughing during or after the examination, and the patient's wet-hoarse voice after drinking were assessed [28]. The test was considered passed if the patient was able to drink continuously without coughing with less than nine swallows and with no voice change. The cause of dysphagia was assessed afterwards in all FEES patients.

\section{Operative Patients}

The operative patients group included dysphagic patients undergoing endoscopic operation because of Zenker's diverticulum, tight cricopharyngeal muscle diagnosed in videofluorography, or both. The operative patients were recruited between September 2018 and October 2020 from four university hospital otorhinolaryngological clinics (Helsinki, Kuopio, Oulu, and Turku). The operations included stapler-assisted diverticuloesophagostomy for Zenker's diverticulum, carbon dioxide $\left(\mathrm{CO}_{2}\right)$ laser cricopharyngeal myotomy, cricopharyngeal dilatation with balloon, or rigid hypopharyngoscopy combined with possible botulinum toxin injection to the muscle. Patients who underwent an operation to cricopharyngeal muscle frequently, for example, cricopharyngeal dilatation due to sequelae of head and neck cancer were excluded. The patients completed F-EAT-10 preoperatively and 3 months postoperatively. The questionnaire also included an additional question regarding possible symptom changes due to operation. This question evaluated whether the change in F-EAT-10 was parallel to subjective symptom change (criterion validity) and was scored from $0-4(0=$ no symptoms, $1=$ less symptoms, $2=$ same symptoms, 3 =slightly more symptoms, $4=$ much more symptoms than before operation).

\section{Questionnaire Acceptance}

Questionnaires with missing answers were not accepted. If the participant selected two adjacent numbers for the same question in F-EAT-10, the mean was calculated and recorded. However, if the participant answered one question with two non-adjacent numbers, the answer was rejected. Only participants with a total F-EAT-10 score in the first questionnaire were included in the study. Participants whose re-questionnaire's total F-EAT-10 score was impossible to calculate were not excluded from the study but their answers in the deficient re-questionnaire were not accepted.

\section{Ethical Considerations}

The participants were given both oral and written information about the study protocol and provided written consent before study entry. The Ethics Committee of the Helsinki and Uusimaa Hospital District approved the study protocol. A research permission was applied in each hospital. This study was conducted in accordance with the Declaration of Helsinki (The World Medical Association 2013).

\section{Statistical Analysis}

The minimum sample size requirement was 100 participants for both FEES patients and controls according to a subject to item ratio of 10:1 [29, 30]. Allowing for a 10\% drop-out rate, the required sample size was increased to 111 participants.

F-EAT-10 scores were reported as means (standard deviation, SD), as this would allow a better description of differences in scores and is also more comparable to other validation studies. Other results (e.g., age) are reported descriptively as frequencies, medians (range), or means (SD) according to the data distribution.

Data from controls and FEES patients were used for internal consistency and reliability analysis. Cronbach's alpha was used to assess the internal consistency of the F-EAT10 baseline questionnaire for controls and FEES patients together and for FEES patients alone. For Cronbach's alpha, values $\geq 0.7$ but $<0.8$ were considered to show acceptable consistency, values $>0.8$ but $<0.9$ good consistency, and values $\geq 0.9$ excellent consistency [31].

The following two methods were used to assess test-retest reliability in FEES patients and controls together and in FEES patients alone: by correlating each question and the total scores in baseline tests and re-tests with a Pearson correlation coefficient and with the intraclass correlation coefficient (ICC). ICC with 95\% confidence intervals (CI) was assessed with a two-way mixed-effect model based on single ratings and absolute agreement. Interpretation was as follows: $<0.50$, poor; between 0.50 and 0.75 , fair; between 0.75 and 0.90 , good; $>0.90$, excellent [32]. Pearson correlation coefficient was used to allow comparison of results with other validation studies. A Pearson correlation $<0.3$ was considered weak, between 0.3 and 0.49 moderate, and $\geq 0.5$ strong [33].

The difference in median age between FEES patients and controls was compared with the Mann-Whitney $U$ test and the difference in gender distribution with chi-square test. The correlation between age and F-EAT-10 scores was assessed with Spearman's rho. The Mann-Whitney $U$ test was used to compare the scores of each of the F-EAT10 questions and the total scores between FEES patients, operative patients, and controls. Based on the data distribution, Spearman's rho was used to assess the correlation 
between the baseline F-EAT-10 total score and the scores for PAS (liquid, nectar, puree, cookie), Yale Pharyngeal Residue Rating Scale (vallecula, pyriform sinus), DOSS, and status findings (saliva retention in vallecula and pyriform sinuses, movements of the lateral pharyngeal walls and the base of the tongue, velopharyngeal closure, vocal fold closure, and sensory testing). Comparisons of the baseline F-EAT-10 total score to findings from FEES patients were assessed with Mann-Whitney $U$ test or Kruskal-Wallis test. Kruskal-Wallis and Mann-Whitney $U$ tests were used for comparisons of the baseline F-EAT-10 total score to aspiration and penetration in PAS and if the patient passed the 100-ml WST, respectively. To determine which F-EAT-10 score would indicate aspiration or penetration in FEES, we used a receiver operating characteristic (ROC) curve with Youden Index, which indicates the maximum potential effectiveness of a biomarker. The subjective symptom changes in FEES patients and operative patients were compared to the change of the total F-EAT-10 score using the Kruskal-Wallis test. The change in the total F-EAT-10 score in operative patients was determined using Wilcoxon signed-rank test. An experienced statistician was consulted regarding the statistical analysis.

All statistical analyses were performed with the IBM SPSS Statistics for Windows (Version 26.0; IBM Corp., Armonk, NY, USA). $P$ values less than 0.05 were considered statistically significant.

\section{Results}

\section{Normative Data}

The median age of the 180 controls was 57.0 years (range 18.3-82.1); 62.2\% was female (Table 2). All 180 F-EAT-10 questionnaires at baseline and the returned re-questionnaires were acceptable. The median time needed to complete the questionnaire was $30 \mathrm{~s}$ (range 10-120). The mean total score of the baseline F-EAT-10 was 0.47 (SD 0.96, range 0-6). According to the original article of Belafsky, the upper limit of the normal cohort was calculated mean $+2 \mathrm{SD}$. For F-EAT-10 this was 2.39, suggesting that the cut-off score for F-EAT-10 is $<3$ (sensitivity $94.0 \%$, specificity $96.1 \%$ ). The total score was 0 in $129(71.7 \%), 1$ in $32(17.8 \%)$, and 2 in $12(6.7 \%)$ controls. Only 7 controls $(3.9 \%)$ scored between 3 and 6 . The re-questionnaire was received from 123 controls $(68.3 \%)$ and the mean F-EAT-10 total score was 0.36 (range $0-4$ ). These 123 re-questionnaires were used in the test-retest reliability analysis. A minor decrease was observed in the total score of the re-questionnaire compared with the baseline scores. The median time to complete the re-questionnaire was 14 days (range 6-36).

\section{FEES Patients}

A total of 127 FEES patients were screened for the study. Nine FEES patients (7.1\%) were excluded from the analysis because their total scores for the baseline F-EAT-10 could not be calculated, and one patient was excluded due
Table 2 Characteristics of patients and controls and mean F-EAT-10 total scores

\begin{tabular}{lllll}
\hline Group & Age $(\mathrm{y})$ & $n(\%)$ & Female $(\%)$ & F-EAT-10 (SD) range \\
\hline Controls & $\leq 20$ & $8(4.4)$ & 62.5 & $1.1(1.5) 0-4$ \\
& $21-40$ & $46(25.6)$ & 58.7 & $0.4(0.8) 0-4$ \\
& $41-60$ & $51(28.3)$ & 64.7 & $0.6(1.1) 0-6$ \\
& $61-79$ & $73(40.6)$ & 61.6 & $0.3(0.7) 0-4$ \\
& $\geq 80$ & $2(1.1)$ & 100.0 & $2.0(2.8) 0-4$ \\
FEES patients & Total & $180(100)$ & 62.2 & $0.5(1.0) 0-6$ \\
& $\leq 20$ & $3(2.6)$ & 66.7 & $13.0(7.2) 5-19$ \\
& $21-40$ & $12(10.3)$ & 75.0 & $14.2(8.4) 2-28$ \\
& $41-60$ & $29(24.8)$ & 55.2 & $14.8(8.0) 0-36$ \\
& $61-79$ & $61(52.1)$ & 44.3 & $16.2(9.3) 0-37$ \\
& $\geq 80$ & $12(10.3)$ & 66.7 & $17.1(12.1) 3.5-38$ \\
Operative patients & $117(100)$ & 53.0 & $15.7(9.1) 0-38$ \\
& $41-60$ & $1(5.3)$ & 0.0 & $21.0(-)$ \\
& $61-79$ & $11(57.9)$ & 72.7 & $22.7(7.6) 11-35$ \\
& $\geq 80$ & $7(36.8)$ & 42.9 & $20.6(4.2) 15-27$ \\
& Total & $19(100)$ & 57.9 & $21.8(6.3) 11-35$ \\
\hline
\end{tabular}

F-EAT-10: Finnish Eating Assessment Tool, FEES: fiberoptic endoscopic evaluating of swallowing, SD: standard deviation 
to age (17 years). In the final analysis, there were 117 FEES patients with median age 69.7 years (range 19.5-90.4), of which $53.0 \%$ was female (Table 2). The baseline F-EAT10 total scores and FEES findings of these 117 patients were evaluated in criterion validity analysis. The re-questionnaire was received from 97 FEES patients (82.9\%), of which $50.5 \%$ was female. Re-questionnaires from five FEES patients $(5.2 \%)$ were not accepted as the total F-EAT-10 scores could not be calculated. These patients were not otherwise excluded from the analysis. Thus, we had 92 re-questionnaires from FEES patients for the test-retest reliability analysis. The mean total score of these re-questionnaires was 14.4 (SD 9.6, range 0-38). The most common causes for dysphagia among all 117 FEES patients were functional $(n=31,26.5 \%)$, head and neck or esophageal malignancies $(n=16,13.7 \%)$, and neurological $(n=15,12.8 \%)$. All FEES patients were eating or drinking orally at least to some extent. The main etiology of dysphagia for FEES patients and the mean total F-EAT-10 scores in different diagnostic groups are presented in Table 3. Some patients have undergone FEES to examine their oropharyngeal dysphagia symptoms or the safety of their swallowing although their main problem may have been esophageal.

\section{Clinical Validity}

There were no differences in gender distribution between controls and FEES patients. While FEES patients were older than controls $(p<0.001)$, age was not significantly correlated to the baseline F-EAT-10 total score in controls $(\mathrm{r}=-0.10$, $p=0.17)$ or FEES patients $(\mathrm{r}=0.11, p=0.24)$. However, in question 3 (swallowing liquids), there was a correlation with age and a higher score in FEES patients $(\mathrm{r}=0.28, p=0.002)$. FEES patients had higher total scores and higher individual question scores than controls; all differences were statistically significant $(p<0.001)$ (Table 2$)$.

\section{Internal Consistency and Reliability}

The internal consistency of the F-EAT-10 total score as assessed by Cronbach's alpha was excellent (0.95) for FEES patients and controls together and good (0.88) for FEES patients alone.

The ICC for determining the test-retest reliability was excellent for the F-EAT-10 total score of FEES patients and controls together $(0.93,95 \%$ CI $0.91-0.95)$. ICC was good for FEES patients alone $(0.84,95 \%$ CI $0.76-0.89)$. Pearson correlation coefficients were statistically significant $(p<0.001)$ for each of the questions and in the baseline F-EAT-10 total scores for FEES patients and for FEES patients and controls together. Pearson correlations were strong in FEES patients and controls together for the baseline F-EAT-10 total score and in each single question. Moreover, Pearson correlations were strong in FEES patients alone for the baseline F-EAT-10 total score and for the single questions. All ICCs and Pearson correlations are presented in Table 4.

\section{Criterion Validity}

For criterion validity assessment, findings from 117 FEES patients were compared to their baseline F-EAT-10 total score. These correlations between PAS (liquid, nectar, puree, cookie) and Yale Pharyngeal Residue Rating Scale (vallecula, pyriform sinus) are presented in Tables 5 and 6 , respectively. In DOSS, a negative correlation with the baseline F-EAT-10 total score was observed $(r=-0.39, p<0.001)$, indicating that patients with normal diet (DOSS 7) had the
Table 3 Etiology of dysphagia in FEES patients and correlations with mean F-EAT10 total scores

\begin{tabular}{lll}
\hline Etiology of dysphagia & $n(\%)$ & F-EAT-10 (SD) range \\
\hline Functional* & $31(26.5)$ & $16.2(9.7) 0-36$ \\
Head and neck or esophageal cancer & $16(13.7)$ & $22.3(6.6) 14-37$ \\
Neurological & $15(12.8)$ & $17.4(9.9) 0-32$ \\
Esophageal (reflux, motility disorders, esophagitis) & $14(12.0)$ & $14.5(9.1) 4-38$ \\
Presbyphagia & $12(10.3)$ & $13.8(7.9) 2-25$ \\
Dry mouth/throat & $9(7.7)$ & $13.2(5.0) 7-21$ \\
Sensation of dysphagia but swallowing is normal & $9(7.7)$ & $6.2(5.0) 0-17$ \\
Compression (goiter, osteophyte, surgical material after ACIF & $3(2.6)$ & $13.3(11.0) 1-22$ \\
$\quad$ operation) & & \\
Cricopharyngeal problem or Zenker's diverticulum & $4(3.4)$ & $20.5(8.2) 10-30$ \\
Other specific reason (EDS, DM, OM, scleroderma) & $4(3.4)$ & $12.0(9.5) 5-25$ \\
\hline
\end{tabular}

$A C I F$ : anterior cervical interbody fusion, DM: dermatomyositis, EDS: Ehlers-Danlos syndrome, F-EAT10: Finnish Eating Assessment Tool, FEES: fiberoptic endoscopic evaluating of swallowing, OM: overlap myositis, $S D$ : standard deviation

*Patient has subjective swallowing problems, but the swallowing is normal 
Table 4 Test-retest reliability in FEES patients and controls

\begin{tabular}{lllll}
\hline F-EAT-10 question & $\begin{array}{l}\text { ICC for FEES patients } \\
(95 \% \mathrm{CI}),\end{array}$ & $\begin{array}{l}\text { Pearson correlations } \\
\text { for FEES patients, } \\
n=117\end{array}$ & $\begin{array}{l}\text { ICC for FEES patients } \\
\text { and controls }(95 \% \mathrm{CI}), \\
n=297\end{array}$ & $\begin{array}{l}\text { Pearson correlation for FEES } \\
\text { patients and controls, } n=297\end{array}$ \\
\hline 1. Weight loss & $0.76(0.66-0.84)$ & $0.76^{*}$ & $0.81(0.75-0.85)$ & $0.81^{*}$ \\
2. Ability to go out for meals & $0.79(0.68-0.86)$ & $0.81^{*}$ & $0.87(0.83-0.90)$ & $0.88^{*}$ \\
3. Swallowing liquids disorder & $0.67(0.54-0.77)$ & $0.68^{*}$ & $0.76(0.69-0.81)$ & $0.76^{*}$ \\
4. Swallowing solids disorder & $0.69(0.56-0.78)$ & $0.69^{*}$ & $0.87(0.83-0.90)$ & $0.87^{*}$ \\
5. Swallowing pills disorder & $0.70(0.58-0.79)$ & $0.71^{*}$ & $0.83(0.79-0.87)$ & $0.83^{*}$ \\
6. Painful swallowing & $0.65(0.52-0.76)$ & $0.65^{*}$ & $0.72(0.64-0.78)$ & $0.72^{*}$ \\
7. Reduced pleasure of eating & $0.70(0.58-0.79)$ & $0.70^{*}$ & $0.84(0.80-0.88)$ & $0.84^{*}$ \\
8. Food sticks in the throat & $0.68(0.47-0.80)$ & $0.72^{*}$ & $0.87(0.82-0.90)$ & $0.88^{*}$ \\
9. Cough during eating & $0.79(0.69-0.85)$ & $0.79^{*}$ & $0.86(0.82-0.89)$ & $0.86^{*}$ \\
10. Stressful swallowing & $0.68(0.56-0.78)$ & $0.69^{*}$ & $0.83(0.78-0.87)$ & $0.83^{*}$ \\
Total score & $0.84(0.76-0.89)$ & $0.84^{*}$ & $0.93(0.91-0.95)$ & $0.93^{*}$ \\
\hline
\end{tabular}

CI: confidence interval, F-EAT-10: Finnish Eating Assessment Tool, FEES: fiberoptic endoscopic evaluating of swallowing, ICC: intraclass correlation coefficient

${ }^{*} p<0.001$

Table 5 Correlation of mean F-EAT-10 total scores to Penetration-Aspiration Scale in FEES patients

\begin{tabular}{lllll}
\hline Consistency & PAS finding** & $n(\%)$ & F-EAT-10 (SD) range & $\begin{array}{l}\text { F-EAT-10 correlation coef- } \\
\text { ficient (Spearman's rho) }\end{array}$ \\
\hline Liquid, $n=115$ & normal & $88(76.5)$ & $14.6(8.3) 0-36$ & 0.17 \\
& penetration & $16(13.9)$ & $17.5(11.2) 0-38$ & \\
& aspiration & $11(9.6)$ & $18.5(9.0) 1-29$ & \\
& penetration or aspiration & $27(23.5)$ & $18.0(10.2) 0-38$ & \\
Nectar, $n=116$ & normal & $97(83.6)$ & $14.7(8.7) 0-38$ & 0.27 \\
& penetration & $16(13.8)$ & $21.3(7.4) 7-34$ & \\
& aspiration & $3(2.6)$ & $20.3(18.1) 1-37$ & \\
Puree, $n=116$ & penetration or aspiration & $19(16.4)$ & $21.2(9.1) 1-37$ & \\
& normal & $97(83.6)$ & $15.0(9.1) 0-38$ & 0.15 \\
& penetration & $19(16.4)$ & $17.8(7.4) 5-29$ & \\
Cookie, $n=108$ & aspiration & $0(0)$ & - & 0.106 \\
& normal & $87(80.6)$ & $14.5(8.6) 0-38$ & 0.10 \\
& penetration & $21(19.4)$ & $15.9(8.0) 1-29$ & \\
& aspiration & $0(0)$ & - & 0.323 \\
\hline
\end{tabular}

F-EAT-10: Finnish Eating Assessment Tool, FEES: fiberoptic endoscopic evaluating of swallowing, PAS: Penetration-Aspiration Scale, SD: standard deviation

${ }^{* *}$ According to the Penetration-Aspiration Scale: normal = PAS 1, penetration = PAS 2-5, aspiration =PAS 6-8

lowest F-EAT-10 total score (Table 7). Based on the ROC curve using Youden Index (data not shown), the F-EAT-10 cut-off score was $\geq 22$ (sensitivity $54.5 \%$, specificity $19.2 \%$ ) for aspiration of liquid in PAS and $\geq 16$ (sensitivity $70.4 \%$, specificity $42.0 \%$ ) for penetration or aspiration. The cut-off score was $\geq 22$ (sensitivity $57.9 \%$, specificity $17.5 \%$ ) for penetration or aspiration for nectar, $\geq 16$ (sensitivity $68.4 \%$, specificity $45.4 \%$ ) for puree, and 16 (sensitivity $61.9 \%$, specificity $42.5 \%$ ) for cookie.
FEES patients who passed $(n=76)$ the 100 -ml WST had a mean baseline F-EAT-10 total score 14.0 (SD 8.4), whereas those who did not pass the test $(n=27)$ had a mean score of 18.2 (SD 9.3). The difference between groups was statistically significant $(p=0.04)$. Moreover, those who coughed $(n=15)$ during the $100-\mathrm{ml}$ WST had a mean baseline F-EAT-10 total score of 23 (SD 8.0) and those who did not cough $(n=88)$ had a mean total score of 13.8 (SD 8.3). This difference was statistically significant $(p=0.001)$. In addition, the F-EAT-10 total score tended to increase if the 
Table 6 Residue findings according to the Yale Pharyngeal Residue Severity Rating Scale and correlations with mean F-EAT-10 total scores

\begin{tabular}{|c|c|c|c|c|c|c|}
\hline Location of Residue & Consistency & Residue severity*** & $n(\%)$ & F-EAT-10 (SD) range & $\begin{array}{l}\text { Spearman's cor- } \\
\text { relation }\end{array}$ & $p$ value \\
\hline \multirow[t]{20}{*}{ Vallecula } & \multirow[t]{5}{*}{ Liquid } & none & 77 (67) & $14.2(8.8) 0-36$ & \multirow[t]{5}{*}{0.21} & \multirow[t]{5}{*}{0.023} \\
\hline & & trace & $24(21)$ & $16.6(7.1) 1-28$ & & \\
\hline & & mild & $13(11)$ & 19.0 (11.4) $0-38$ & & \\
\hline & & moderate & $1(1)$ & $29(-)-$ & & \\
\hline & & severe & $0(0)$ & - & & \\
\hline & \multirow[t]{5}{*}{ Nectar } & none & $70(60)$ & 14.9 (8.9) $0-36$ & \multirow[t]{5}{*}{0.15} & \multirow[t]{5}{*}{0.112} \\
\hline & & trace & $29(25)$ & $15.7(8.2) 1-38$ & & \\
\hline & & mild & $14(12)$ & $19.1(9.9) 0-34$ & & \\
\hline & & moderate & $2(2)$ & $14.0(12.7) 5-23$ & & \\
\hline & & severe & $1(1)$ & $37(-)-$ & & \\
\hline & \multirow[t]{5}{*}{ Puree } & none & $47(41)$ & $13.7(8.5) 0-36$ & \multirow[t]{5}{*}{0.21} & \multirow[t]{5}{*}{0.027} \\
\hline & & trace & $32(28)$ & 15.5 (9.3) $0-36$ & & \\
\hline & & mild & $21(18)$ & 16.5 (6.6) 5-27 & & \\
\hline & & moderate & $13(11)$ & $19.1(10.7) 0-38$ & & \\
\hline & & severe & $3(3)$ & 20.7 (14.6) 5-34 & & \\
\hline & \multirow[t]{5}{*}{ Cookie } & none & $42(39)$ & $14.5(8.3) 0-36$ & \multirow[t]{5}{*}{0.10} & \multirow[t]{5}{*}{0.290} \\
\hline & & trace & $21(20)$ & $11.4(7.8) 0-25$ & & \\
\hline & & mild & $26(24)$ & $17.0(8.3) 1-36$ & & \\
\hline & & moderate & $14(13)$ & $16.5(10.1) 0-38$ & & \\
\hline & & severe & $4(4)$ & $14.8(6.7) 5-20$ & & \\
\hline \multirow{20}{*}{$\begin{array}{l}\text { Pyriform } \\
\text { sinus }\end{array}$} & \multirow[t]{5}{*}{ Liquid } & none & $81(70)$ & 14.1 (8.7) 0-36 & \multirow[t]{5}{*}{0.22} & \multirow[t]{5}{*}{0.020} \\
\hline & & trace & $20(17)$ & 17.8 (7.8) $7-32$ & & \\
\hline & & mild & $12(10)$ & 18.9 (10.7) $0-38$ & & \\
\hline & & moderate & $1(1)$ & $14(-)-$ & & \\
\hline & & severe & $1(1)$ & $29(-)-$ & & \\
\hline & \multirow[t]{5}{*}{ Nectar } & none & 77 (66) & 14.5 (8.8) $0-36$ & \multirow[t]{5}{*}{0.18} & \multirow[t]{5}{*}{0.050} \\
\hline & & trace & $25(22)$ & 18.4 (8.3) 5-38 & & \\
\hline & & mild & $8(7)$ & 13.5 (6.7) 5-24 & & \\
\hline & & moderate & $5(4)$ & 21.0 (13.3) $0-34$ & & \\
\hline & & severe & $1(1)$ & $37(-)-$ & & \\
\hline & \multirow[t]{5}{*}{ Puree } & none & $66(57)$ & 13.8 (8.3) $0-36$ & \multirow[t]{5}{*}{0.24} & \multirow[t]{5}{*}{0.011} \\
\hline & & trace & $21(18)$ & 15.6 (9.6) $0-35$ & & \\
\hline & & mild & $19(16)$ & $20.3(8.4) 6-38$ & & \\
\hline & & moderate & $9(8)$ & 15.8 (9.5) $0-28$ & & \\
\hline & & severe & $1(1)$ & $29(-)-$ & & \\
\hline & \multirow[t]{5}{*}{ Cookie } & none & $62(58)$ & 13.3 (8.5) $0-36$ & \multirow[t]{5}{*}{0.23} & 0.018 \\
\hline & & trace & $22(21)$ & $16.1(8.7) 1-38$ & & \\
\hline & & mild & $12(11)$ & 17.6 (7.0) 5-28 & & \\
\hline & & moderate & $10(9)$ & $17.3(9.4) 0-29$ & & \\
\hline & & severe & $1(1)$ & $16(-)-$ & & \\
\hline
\end{tabular}

F-EAT-10: Finnish Eating Assessment Tool, SD: standard deviation

*** According to the Yale Pharyngeal Residue Severity Rating Scale

patient coughed after the 100-ml WST or if the patient's voice became wet-hoarse, although these differences were not statistically significant $(p=0.08$, and $p=0.32$, respectively).
In status findings, there was a positive correlation with saliva retention in vallecula and pyriform sinuses and baseline F-EAT-10 total scores $(r=0.27$, and $r=0.29$, respectively, $p<0.001$ ). A statistically significant difference was also observed between normal and abnormal movements 
Table 7 Dysphagia Outcome Severity Scale ratings and correlations with mean F-EAT10 total scores in FEES patients

\begin{tabular}{llll}
\hline DOSS rating & $n(\%)$ & F-EAT-10 (SD) range & $\begin{array}{l}\text { F-EAT-10 Correlation } \\
\text { coefficient (Spearman's } \\
\text { rho) }\end{array}$ \\
\hline Total & 117 & $15.7(9.1) 0-38$ & $-0.39 *$ \\
Level 7: Normal in all situations & $43(36.8)$ & $11.9(9.1) 0-38$ & \\
Level 6: Within functional limits & $35(29.9)$ & $15.3(8.7) 0-36$ & \\
Level 5: Mild dysphagia & $21(17.9)$ & $19.1(8.6) 1-38$ & \\
Level 4: Mild-moderate dysphagia & $12(10.3)$ & $18.4(11.0) 0-36$ & \\
Level 3: Moderate dysphagia & $4(3.4)$ & $25.8(6.1) 18-32$ & \\
Level 2: Moderately severe dysphagia & $1(0.9)$ & $23(-)-$ & \\
Level 1: Severe dysphagia & $1(0.9)$ & $37(-)-$ & \\
\hline
\end{tabular}

DOSS: Dysphagia Outcome Severity Scale, F-EAT-10: Finnish Eating Assessment Tool, FEES: fiberoptic endoscopic evaluating of swallowing, $S D$ : standard deviation ${ }^{*} p<0.001$ of the lateral pharyngeal walls and F-EAT-10 total scores $(p=0.02)$. However, no statistically significant differences were noted between the F-EAT-10 total score and normal versus abnormal findings in velopharyngeal closure, movement of the base of the tongue, vocal fold closure, or sensory testing on the tip of the epiglottis or on the arytenoids.

Of the 92 FEES patients who returned re-questionnaire, 73 (53.4\% female) also answered the question regarding possible symptom changes during the 2-week follow-up. Most of the FEES patients felt their symptoms were unchanged $(n=42,57.5 \%)$ or felt a slight symptom improvement $(n=20,27.4 \%)$. Only a few patients considered their symptoms as slightly worse $(n=6,8.2 \%)$ or absent $(n=5,6.8 \%)$. The median F-EAT-10 total score change decreased in those who experienced less symptoms (-0.5), the same symptoms $(-0.5)$, or were asymptomatic $(-5.0)$, but increased among those who experienced more symptoms $(0.5)$. However, this result was not statistically significant $(p=0.61)$.

\section{Operative Patients}

Of the 22 operative patients, the re-questionnaire was received from 21 patients $(95.5 \%)$. Of these 19 answered every question, including the question concerning possible symptom changes after the operation. The data from these 19 patients (median age 75.8 years, range 56.4-87.1, 57.9\% female) were used in criterion validity analysis. The characteristics of operative patients and mean F-EAT-10 total scores are presented in Table 2. Cricopharyngeal balloon dilatation was performed on nine patients, of which one also had botulinum toxin injection, seven patients had staplerassisted operation of Zenker's diverticulum, two patients had cricopharyngeal myotomy performed with $\mathrm{CO}_{2}$ laser, and one patient underwent cricopharyngeal dilatation with rigid hypopharyngoscopy combined with botulinum toxin injection. The mean F-EAT-10 score was 21.8 (SD 6.3, range 11-35) at baseline and 11.4 (SD 10.0, range 0-31) after a 3-month follow-up and the change in scores was statistically significant $(p<0.001)$. Most of the patients felt that they were asymptomatic $(n=10,52.6 \%)$ or had less symptoms $(n=8,42.1 \%)$ than before operation. One patient (5.3\%) felt that her symptoms were unchanged. No patients experienced more symptoms. The median F-EAT-10 total score decreased in those who experienced less symptoms $(-7.0)$ or were asymptomatic (-17.5). The F-EAT-10 score did not change in the patient who felt her symptoms were unchanged. However, possible due to small number of operative patients, this result was not statistically significant $(p=0.31)$.

\section{Discussion}

Our results indicate that F-EAT-10 is a valid patient-reported outcome measure for dysphagia. This study showed a significant difference in total scores between controls and dysphagia patients and in each of the 10 questions, thus indicating the validity of F-EAT-10 as a screening tool. Most of the controls had scores of 0 in F-EAT-10 and mean score was 0.47 , which is consistent with the previous validation studies $[13-16,18,19,22]$. The cut-off score for our controls was determined $<3$ points suggesting that $\geq 3$ is abnormal, consistent with the original article of Belafsky and in many other validation projects $[13,15,16,19]$. However, there are some EAT-10 studies where the cut-off score was 2 $[18,34]$. Although a few of our controls scored $>2$ points, they all reported having no deglutition problems during an interview by the nurse. However, one or more questions in F-EAT-10 reminded them of some previous problems they recorded, but this was not a reason for exclusion from the study. However, it would be useful to have a time interval in EAT-10 (e.g., asking about symptoms in the previous 
month) in which the subject evaluates his or her symptoms of deglutition.

There were no missing values in the F-EAT-10 questionnaires from controls, which indicates that the questions were easy to answer for asymptomatic subjects. Moreover, the median time to complete F-EAT-10 for controls was only $30 \mathrm{~s}$, suggesting that F-EAT-10 is feasible as demonstrated in other studies [13-18]. However, some baseline questionnaires (7.1\%) and re-questionnaires (5.2\%) from FEES patients were not answered correctly and thus the total scores were not countable. This result is similar to that of the S-EAT-10 validation project (7\%) [19]. In general, missing answers were rare and, differed between questions, indicating that there are no specific questions that are difficult to answer. In some studies, participants without proper reading skills or with a severe neurological disease or dementia have been excluded [19, 22]. This is consistent with our exclusion criteria, in which participants unable to complete the questionnaire independently or with any notable psychiatric or cognitive disease are not eligible. Our observation suggests that F-EAT-10 is easy to complete among our study population. Re-questionnaires were received more often from FEES patients $(n=97,82.9 \%)$ and operative patients $(n=21$, $95.5 \%)$ than from controls $(n=123,68.3 \%)$. All participants received a text message or a phone call as a reminder, but we assume that asymptomatic subjects were less motivated to complete and return the re-questionnaires than patients.

The Cronbach's alpha value (0.95) was excellent for the total F-EAT-10 score in controls and FEES patients together and was also good for FEES patients alone (0.84), indicating an excellent to good internal consistency. According to the previous validations, Cronbach's alpha for the total EAT-10 score varied from 0.87 (Sp-EAT-10) to 0.96 (the original EAT-10 of Belafsky), suggesting that our result is consistent with these previous studies [13-19, 22, 35]. The ICC indicating test-retest reliability was $0.93(0.91-0.95)$ for both controls and FEES patients together and $0.84(0.76-0.89)$ for FEES patients alone, indicating excellent to good reproducibility. In the original article of EAT-10, ICC ranged from 0.72 to 0.91 and the highest ICCs were approximately 0.90 for the total score $[18,19]$. Nevertheless, the I-EAT-10 total score reached ICCs as high as 0.95 (patients) and 0.98 (controls). In FEES patients and controls together, Pearson correlations were strong for the total score $(0.93)$ and in every single question $(0.72-0.88)$, consistent with the previous studies [15-17, 19, 22, 36]. In addition, Pearson correlations were strong for the total score $(0.84)$ and every single question (0.65-0.81) for FEES patients alone. Our FEES patients completed the re-questionnaire after a 2-week follow-up. As the FEES procedure is usually followed by instructions to help deglutition and because the patient's dysphagia symptoms may fluctuate, we asked about possible symptom change in the re-questionnaire. Although some patients reported symptom changes, some FEES patients did not answer this question and, we cannot exclude the possibility that their symptoms might also have changed. This is a probable explanation for why our test-retest results did not reach as high ICCs and correlations as observed in other studies $[15,18,35]$.

The mean F-EAT-10 total score was different between diagnostic groups. Patients without significant findings in FEES had the lowest total scores and those with a neurological cause or a malignancy had the highest total scores. Patients with dry mucous membranes/xerostomia, or presbyphagia, had elevated, but not very high total scores. Thus, F-EAT-10 scores were as expected in different diagnostic groups.

For the criterion validity assessment, we prospectively collected numerous findings in FEES to compare with the F-EAT-10 total score. While we found some statistically significant correlations in PAS and the Yale Pharyngeal Residue Rating Scale, the correlations were mainly weak. In DOSS, negative and moderate correlations were evident, indicating that F-EAT-10 total scores increased with poorer swallowing. Moreover, some positive correlations were found in the status findings. Our results were similar to those of the Hebrew EAT-10 (EAT-10 ${ }_{\mathrm{Heb}}$ ) validation study, where weak correlations with EAT-10 scores and pathological findings in FEES were found [37]. Additionally, in the I-EAT-10 validation, weak correlations with EAT-10 total score and DOSS and with PAS in semisolids were observed [15]. In a recently published study, mild-to-moderate correlations were found between EAT-10 and PAS scores depending on the patient's diagnosis. Higher EAT-10 scores were also significantly correlated with higher PAS scores. However, these patients underwent videofluoroscopy [38]. Thus, we conclude that objective findings in FEES may also correlate with subjective patient symptoms, although the correlations were mainly weak in our study.

We also wanted to study whether the F-EAT-10 total score can predict aspiration risk. As the causes for dysphagia were usually benign in our FEES patients (e.g., functional, presbyphagia, dry mouth, or throat) or esophageal, there were only a few patients who aspirated. As no FEES patients aspirated with puree or cookie and only three with nectar, the cut-off scores were mainly determined for penetration (PAS $>1$ ) and thus included possible aspiration. An F-EAT10 total score of $\geq 16$ was the cut-off score for penetration (PAS $>1$ ) with liquid, puree, or cookie; the corresponding score was $\geq 22$ with nectar (ROC curves). Due to the small number of FEES patients with PAS $>1$, the sensitivity and specificity were not usually high. Moreover, we used the Youden Index, which works best if there are approximately the same number of patients with and without the finding. Although some previous studies have concluded that EAT10 scores may predict aspiration $[7,18,22,38-40]$, there are 
also contrary results [41]. The heterogeneity of the patient groups and study settings also makes comparisons across studies challenging. Belafsky's group observed aspiration $(\mathrm{PAS}>5)$ in videofluoroscopic swallowing studies and concluded that a cut-off score of 16 reached a sensitivity of $71 \%$ and specificity of 53\%. However, their patient group was heterogenous and included patients with esophageal dysphagia [39]. Taken together, there is no consensus of the cut-off score for aspiration and further studies are needed.

WST is a rapid screening tool for dysphagia [28, 42]. Thus, we also studied the results of the 100-ml WST of FEES patients and correlations to F-EAT-10 total score. In FEES patients who passed the test, a statistically significant difference was observed in F-EAT-10 total score compared with those who did not pass. Moreover, a statistically significant difference in F-EAT-10 total score was observed among those who did not cough during the test compared with those who did cough. Our result suggests that the 100-ml WST along with F-EAT-10 may predict swallowing problems, as demonstrated in recently published studies [43, 44].

We aimed to test whether F-EAT-10 can capture possible subjective symptom changes during a 2-week (FEES patients) or a 3-month (operative patients) follow-up period, indicating another aspect of criterion-based validity. The F-EAT-10 total score decreased in those FEES patients who experienced less symptoms, the same symptoms, or were asymptomatic and increased among those who experienced more symptoms. However, the result was not statistically significant, possibly because of the small number of FEES patients in the two subgroups (asymptomatic and slightly more symptoms). F-EAT-10 scores captured symptom changes in operative patients in most cases. Thus, F-EAT10 can also be used to evaluate patient symptoms after an endoscopic operation on Zenker's diverticulum, tight cricopharyngeal muscle diagnosed in videofluorography, or both.

There are some limitations to the present study. Some questionnaires were excluded because of missing or uninterpretable answers. Among operative patients, subjective symptom changes in some patients did not parallel changes in the F-EAT-10 score and the number of operative patients was low. Evaluation of subjective symptom changes after operative treatment might be more accurate if asked after a shorter time than 3 months. This study was a multicenter study, as the need to validate a Finnish dysphagia outcome tool was nationwide. However, only a few FEES patients were recruited in some hospitals and most patients and all controls were from the Helsinki University Hospital. There were 12 professionals who performed FEES, which may influence the interpretation of FEES findings. On the other hand, F-EAT-10 performed well despite 12 colleagues participating in the study. Moreover, well-known classifications were used, which should make the results more congruent.

\section{Conclusions}

We validated F-EAT-10 in asymptomatic controls and in FEES patients with different dysphagia etiologies and in dysphagia patients who underwent an endoscopic procedure. Our results indicate that F-EAT-10 is a valid instrument to evaluate deglutition problems and is also applicable for follow-up. F-EAT-10 can be helpful in identifying patients who are at risk for penetration and aspiration. In addition, there are some correlations between patients' subjective symptoms measured by F-EAT-10 and objective findings in FEES.

Acknowledgements The authors gratefully acknowledge phoniatrician, ENT specialist Anu Jyrkkä; ENT specialist Juhani Pöntinen; speech and language pathologists: Minna Apajalahti, Tiina Pakka, Kaarina Ruusuvirta, Tarja Karttunen, and Sanna Remes who participated in data collection for this research; nurses: Fariba Akdeniz, Elisa Kesäläinen, Sanna Mäki, and Mirja Tamminen for recruiting the patients in Turku University Hospital, Tero Vahlberg, and Paula Bergman for assistance with statistical analyses; and Catharina Pomoell for data collection and technical assistance.

Funding Open access funding provided by University of Helsinki including Helsinki University Central Hospital. This study was funded by the Helsinki University Hospital Research Funds (Grant No. Y1014KN011), the Finnish Society for Laryngology and the Finnish Association of Otorhinolaryngology - Head and Neck Surgery (Grant No. 20180024).

\section{Declarations}

Conflict of interest All authors declare that they have no conflicts of interest.

Ethical Approval All procedures performed in studies involving human participants were in accordance with the ethical standards of the institutional research committee and with the 1964 Helsinki declaration and its later amendments or comparable ethical standards.

Informed Consent Informed consent was obtained from all individual participants included in the study.

Open Access This article is licensed under a Creative Commons Attribution 4.0 International License, which permits use, sharing, adaptation, distribution and reproduction in any medium or format, as long as you give appropriate credit to the original author(s) and the source, provide a link to the Creative Commons licence, and indicate if changes were made. The images or other third party material in this article are included in the article's Creative Commons licence, unless indicated otherwise in a credit line to the material. If material is not included in the article's Creative Commons licence and your intended use is not permitted by statutory regulation or exceeds the permitted use, you will need to obtain permission directly from the copyright holder. To view a copy of this licence, visit http://creativecommons.org/licenses/by/4.0/. 


\section{References}

1. Bloem BR, Lagaay AM, van Beek W, Haan J, Roos RA, Wintzen AR. Prevalence of subjective dysphagia in community residents aged over 87. BMJ. 1990;300(6726):721-2. https://doi.org/10. 1136/bmj.300.6726.721.

2. Lindgren S, Janzon L. Prevalence of swallowing complaints and clinical findings among 50-79-year-old men and women in an urban population. Dysphagia. 1991;6(4):187-92. https://doi.org/ 10.1007/BF02493524.

3. Clavé P, Rofes L, Carrión S, Ortega O, Cabré M, Serra-Prat M, et al 2012 Pathophysiology, Relevance and Natural History of Oropharyngeal Dysphagia among Older People. In: Stepping Stones to Living Well with Dysphagia. Basel, Switzerland: S. Karger AG, pp 57-66

4. Clavé P, Shaker R. Dysphagia: current reality and scope of the problem. Nat Rev Gastroenterol Hepatol. 2015;12(5):259-70. https://doi.org/10.1038/nrgastro.2015.49.

5. Meng NH, Wang TG, Lien IN. Dysphagia in patients with brainstem stroke: incidence and outcome. Am J Phys Med Rehabil. 2000;79(2):170-5. https://doi.org/10.1097/00002060-20000 3000-00010.

6. Ekberg O, Hamdy S, Woisard V, Wuttge-Hannig A, Ortega P. Social and psychological burden of dysphagia: its impact on diagnosis and treatment. Dysphagia. 2002;17(2):139-46. https://doi. org/10.1007/s00455-001-0113-5.

7. Rofes L, Arreola V, Almirall J, Cabré M, Campins L, García-Peris P, Speyer R, Clavé P. Diagnosis and management of oropharyngeal dysphagia and its nutritional and respiratory complications in the elderly. Gastroenterol Res Pract. 2011. https://doi.org/10. 1155/2011/818979.

8. Wilson RD. Mortality and cost of pneumonia after stroke for different risk groups. J Stroke Cerebrovasc Dis. 2012;21(1):61-7. https://doi.org/10.1016/j.jstrokecerebrovasdis.2010.05.002.

9. Timmerman AA, Speyer R, Heijnen BJ, Klijn-Zwijnenberg I. Psychometric characteristics of health-related quality-of-life questionnaires in oropharyngeal dysphagia. Dysphagia. 2014;29(2):18398. https://doi.org/10.1007/s00455-013-9511-8.

10. McHorney CA, Robbins J, Lomax K, Rosenbek JC, Chignell K, Kramer AE, et al. The SWAL-QOL and SWAL-care outcomes tool for oropharyngeal dysphagia in adults: III. Doc Reliab Valid Dysphagia. 2002;17(2):97-114. https://doi.org/10.1007/ s00455-001-0109-1.

11. Silbergleit AK, Schultz L, Jacobson BH, Beardsley T, Johnson $\mathrm{AF}$. The dysphagia handicap index: development and validation. Dysphagia. 2011;27(1):46-52. https://doi.org/10.1007/ s00455-011-9336-2.

12. Chen AY, Frankowski R, Bishop-Leone J, Hebert T, Leyk S, Lewin J, Goepfert H. The development and validation of a dysphagia-specific quality-of-life questionnaire for patients with head and neck cancer: The M D Anderson dysphagia inventory. Arch Otolaryngol Head Neck. 2001;127(7):870-6.

13. Belafsky PC, Mouadeb DA, Rees CJ, Pryor JC, Postma GN, Allen J, Leonard R. Validity and reliability of the eating assessment tool (EAT-10). Ann Otol Rhinol Laryngol. 2008;117(12):919-24. https://doi.org/10.1177/000348940811701210.

14. Burgos R, Sarto B, Segurola H, Romagosa A, Puiggrós C, Vázquez $\mathrm{C}$, et al. Translation and validation of the Spanish version of the EAT-10 (Eating Assessment Tool-10) for the screening of dysphagia. Nutr Hosp. 2012;27(6):2048-54. https://doi.org/10. 3305/nh.2012.27.6.6100.

15. Schindler A, Mozzanica F, Monzani A, Ceriani E, Atac M, JukicPeladic N, Venturini C, Orlandoni P. Reliability and validity of the Italian eating assessment tool. Ann Otol Rhinol Laryngol.
2013;122(11):717-24. https://doi.org/10.1177/000348941312201 109.

16. Nogueira D, Ferreira P, Reis E, Lopes I. Measuring outcomes for dysphagia: validity and reliability of the European Portuguese eating assessment tool (P-EAT-10). Dysphagia. 2015;30(5):511-20. https://doi.org/10.1007/s00455-015-9630-5.

17. Demir N, Serel Arslan S, İnal Ö, Karaduman AA. Reliability and validity of the Turkish eating assessment tool (T-EAT10). Dysphagia. 2016;31(5):644-9. https://doi.org/10.1007/ s00455-016-9723-9.

18. Giraldo-Cadavid L, Gutiérrez-Achury AM, Ruales-Suárez K, Rengifo-Varona M, Barros C, Posada A, et al. Validation of the Spanish version of the eating assessment tool-10 (EAT-10spa) in Colombia. A Blinded Prospective Cohort Study Dysphagia. 2016;31(3):398-406. https://doi.org/10.1007/s00455-016-9690-1.

19. Möller R, Safa S, Östberg P. Validation of the Swedish translation of eating assessment tool (S-EAT-10). Acta Otolaryngol. 2016;136(7):749-53. https://doi.org/10.3109/00016489.2016. 1146411.

20. Printza A, Kyrgidis A, Pavlidou E, Triaridis S, Constantinidis J. Reliability and validity of the eating assessment tool-10 (Greek adaptation) in neurogenic and head and neck cancerrelated oropharyngeal dysphagia. Eur Arch Otorhinolaryngol. 2018;275(7):1861-8. https://doi.org/10.1007/s00405-018-5001-9.

21. Chung CYJ, Perkisas S, Vandewoude MFJ, De Cock AM. Validation of the Dutch EAT-10 for screening of oropharyngeal dysphagia in the elderly population. Tijdschr Gerontol Geriatr. 2019. https://doi.org/10.36613/tgg.1875-6832/2019.04.03.

22. Lechien JR, Cavelier G, Thill M, Huet K, Harmegnies B, Bousard L, et al. Validity and reliability of the French version of Eating Assessment Tool (EAT-10). Eur Arch Otorhinolaryngol. 2019;276(6):1727-36. https://doi.org/10.1007/ s00405-019-05429-1.

23. Wild D, Grove A, Martin M, Eremenco S, McElroy S, VerjeeLorenz A, et al. Principles of good practice for the translation and cultural adaptation process for patient-reported outcomes (PRO) measures: report of the ispor task force for translation and cultural adaptation. Value Health. 2005;8(2):94-104. https://doi.org/10.1111/j.1524-4733.2005.04054.x.

24. Langmore SE, Schatz K, Olsen N. Fiberoptic endoscopic examination of swallowing safety: a new procedure. Dysphagia. 1988;2(4):216-9. https://doi.org/10.1007/BF02414429.

25. Neubauer P, Rademaker A, Leder S. The Yale pharyngeal residue severity rating scale: an anatomically defined and imagebased tool. Dysphagia. 2015;30(5):521-8. https://doi.org/10. 1007/s00455-015-9631-4.

26. Rosenbek JC, Robbins JA, Roecker EB, Coyle JL, Wood JL. A penetration-aspiration scale. Dysphagia. 1996;11(2):93-8. https://doi.org/10.1007/BF00417897.

27. O'Neil KH, Purdy M, Falk J, Gallo L. The dysphagia outcome and severity scale. Dysphagia. 1999;14(3):139-45. https://doi. org/10.1007/PL00009595.

28. DePippo KL, Holas MA, Reding MJ. Validation of the 3-oz water swallow test for aspiration following stroke. Arch Neurol. 1992;49(12):1259-61. https://doi.org/10.1001/archneur.1992. 00530360057018.

29. Nunnally J. Psychometric theory. 2nd ed. New York: McGrawHill; 1978.

30. Bentler PM, Chou C. Practical Issues in Structural Modeling. Sociol Methods Res. 1987;16(1):78-117.

31. George D, Mallery P 2005 SPSS for Windows Step by Step: A Simple Guide and Reference, 12.0 update, 5th ed. Reference \& Research Book News 20(2):93

32. Koo TK, Li MY. A guideline of selecting and reporting intraclass correlation coefficients for reliability research. J Chiropr 
Med. 2016;15(2):155-63. https://doi.org/10.1016/j.jcm.2016. 02.012 .

33. Cohen Ventura J. Statistical power analysis for the behavioral sciences. 2nd ed. Hillsdale (NJ): Lawrence Erlbaum; 1988.

34. Rofes L, Arreola V, Mukherjee R, Clavé P. Sensitivity and specificity of the eating assessment tool and the volume-viscosity swallow test for clinical evaluation of oropharyngeal dysphagia. Neurogastroenterol Motil. 2014;26(9):1256-65. https://doi.org/ 10.1111/nmo.12382.

35. Abu-Ghanem S, Schechter M, Flesh-Eyni H, Litwin L, Makai E, Oestreicher-Kedem Y, Yehuda M. Validation of the Hebrew version of the eating assessment tool-10 (H-EAT-10). Folia Phoniatr Logop. 2016;68(6):261-7. https://doi.org/10.1159/000484557.

36. Farahat M, Mesallam TA. Validation and cultural adaptation of the Arabic version of the eating assessment tool (EAT-10). Folia Phoniatr Logop. 2016;67(5):231-7. https://doi.org/10.1159/00044 2199.

37. Shapira-Galitz Y, Yousovich R, Halperin D, Wolf M, Lahav Y, Drendel M. Does the Hebrew eating assessment tool-10 correlate with pharyngeal residue, penetration and aspiration on fiberoptic endoscopic examination of swallowing? Dysphagia. 2019;34(3):372-81. https://doi.org/10.1007/s00455-018-9964-x.

38. Bartlett RS, Kenz MK, Wayment HA, Thibeault SL. Correlation between eAT-10 and aspiration risk differs by dysphagia etiology. Dysphagia. 2021. https://doi.org/10.1007/s00455-021-10244-0.

39. Cheney DM, Siddiqui MT, Litts JK, Kuhn MA, Belafsky PC. The ability of the 10-item eating assessment tool (EAT-10) to predict aspiration risk in persons with dysphagia. Ann Otol Rhinol Laryngol. 2014;124(5):351-4. https://doi.org/10.1177/0003489414 558107.
40. Arslan SS, Demir N, Kılınç HE, Karaduman AA. The ability of the eating assessment tool-10 to detect aspiration in patients with neurological disorders. J Neurogastroenterol Motil. 2017;23(4):550-4. https://doi.org/10.5056/jnm16165.

41. Kendall K. Objective measures of swallowing function applied to the dysphagia population: a one year experience. Dysphagia. 2016;31(4):538-46. https://doi.org/10.1007/s00455-016-9711-0.

42. Wu MC, Chang YC, Wang TG, Lin LC. Evaluating swallowing dysfunction using a $100-\mathrm{ml}$ water swallowing test. Dysphagia. 2004;19(1):43-7. https://doi.org/10.1007/s00455-003-0030-x.

43. Nishida T, Yamabe K, Ide Y, Honda S. Utility of the eating assessment tool-10 (EAT-10) in evaluating self-reported dysphagia associated with oral frailty in Japanese community-dwelling older people. J Nutr Health Aging. 2020;24(1):3-8. https://doi.org/10. 1007/s12603-019-1256-0.

44. de Sire A, Giachero A, De Santi S, Inglese K, Solaro C. Screening dysphagia risk in 534 older patients undergoing rehabilitation after total joint replacement. A cross-sectional study. Eur J Phys Rehabil Med. 2021;57(1):131-6. https://doi.org/10.23736/S19739087.20.06321-2.

Publisher's Note Springer Nature remains neutral with regard to jurisdictional claims in published maps and institutional affiliations.

Pia Järvenpää MD, PHD 